\title{
Construction of Scholarship and Grants System under the Background of Reform of Postgraduate Training Mechanism
}

\author{
Weifeng $\mathrm{Li}^{1}$, a, Lixia Liang ${ }^{2, b}$ \\ ${ }^{1}$ School Of Political Science And Law University Of Jinan, Shandong 250022, China; \\ ${ }^{2}$ School Of Political Science And Law University Of Jinan, Shandong 250022, China. \\ aliweifeng96@163.com, b|llxia76@163.com
}

Keywords: postgraduate education,scholarship and grants system.

\begin{abstract}
Postgraduate education is the highest level in higher education, and it shoulders the mission to cultivate top-notch and high-quality talent. Scholarship and Grants are basic guarantees for postgraduates to live and complete their studies. Only by constructing a well-developed scholarship and grants system, can graduate students feel relieved and reduce their economic burdens. This paper analyzes the implementation situation of the current scholarship and grants systems in some universities, and builds a new and reasonable system based on this, and proposes corresponding reference opinions.
\end{abstract}

\section{Introduction}

In 1978, China resumed postgraduate enrollment. Since then, scholarship and grants systems of postgraduate have undergone several changes. From 1978 to 1993, the state implemented a single mode of grant. There is no need to pay any fees for postgraduate study with a certain amount of subsidies. Since 1993, the state's cultivation of postgraduates has been divided into four categories, which includes non-directional enrollment under the state plan, non-directional enrollment, commissioned enrollment, and self-funded enrollment. The state will no longer undertake the commissioned enrollment and self-funded enrollment. The implementation of this policy marks that the graduate training fund is no longer entirely borne by the government. In 2006, the State initiated the pilot reform of postgraduate training mechanism. Each school focused on the goal of "optimizing the type and structure of postgraduate education and improving the quality of postgraduate education" and actively explored scientific practice. Since 2013, the country has successively issued a series of documents based on the situation, aiming at advancing postgraduate education reform, innovating training model, and strengthening quality assurance. In view of this, scholarship and grants systems and investment in education have become important topics and directions for postgraduate education reform in universities.

\section{The scholarship and grants systems in some universities under the new situation}

In view of different conditions of each university, the scholarship and grants systems have also presented various, but the overall goal is to improve the quality of postgraduates and focus on improving the treatment of postgraduates and encouraging outstanding people, allocating scholarship and grants rationally and funding poverty and other aspects to build a reward system.

In 2007, Fudan University joined the experimental reform of postgraduates training mechanism, with tutor-responsibility system and tutor funding system as the core, reformed the selection mechanism, optimized the training process, strengthened the construction of instructors, improved the funding system, and comprehensively improved the quality of postgraduate training. Its scholarship and grants system has four major features: full utilizing mentors, improving student treatment, stimulating research enthusiasm, and reflecting differences in disciplines. Peking University adhered to the working principle of "stabilizing scale, optimizing structure, and improving quality" to advance the work of postgraduates in an all-round way. It was based on academic scholarships and assistant research posts, supplemented by assistant teaching posts and 
special scholarships, and characterized by the control of enrollment plans. Shandong University implemented four reforms, including the diversification of funding sources, and construction of a combination scholarship and grants systems shared by the state, universities and mentors, the launch of incentive mechanism and establishment of standardized and perfect postgraduate scholarship system; optimization of the evaluation system to guide graduate students to establish correct value orientation. Based on full coverage, Nanjing Agricultural University has also carried out a series of reform measures with people-orientation to guarantee the basic living conditions of postgraduates; as a means to encourage graduate students to fight for the first class; and ensures that the process of scholarship and grants system must be fair.

As a whole, colleges and universities are generally based on and combined with their specific realities, and at the same time follow the changes of the national policy situation, formulate policies and measures that are consistent with the development of the university, and build a rewarding system of graduate student compatible with the school itself, which smoothly promotes the progress of work. The development has also greatly improved the quality and level of graduate students.

\section{Problems in the graduate student scholarship and grants system in colleges and universities}

\subsection{Prominent contradiction between the supply and demand of funds}

In 2013, the Ministry of Education and other three ministries jointly promulgated the "Opinions on Deepening the Reform of Postgraduate Education" and clearly put forward that the investment mechanism for graduate students should be improved, which comes into being a mechanism conducted mainly by government, educators' rational sharing of training costs, and training units to raise funds through multiple channels, aiming to build a diversified and long-term postgraduate mechanism. With the increasing number of graduate students and the increase in the cost of postgraduate research, the government's budget for graduate students is relatively limited, many colleges and universities often feel that ability is not equal to one's ambition when they meet the increasing demands of graduate students, and it's difficult to support, there is a prominent contradiction between the supply and demand of funds.

\subsection{The significant difference in the scholarship and grants system for different disciplines}

Different disciplines such as liberal arts, science, and medicine also have significant differences in the evaluation of grants. Many universities have different degrees of emphasizing on science and engineering but ignoring the importance of humanities and social sciences. The prizes for science and engineering students participating in research competitions or relevant competitions are significantly higher than the liberal arts students. At the same time, science and engineering students are relatively easy to apply for funding for scientific research projects, and the amount that can be applied for is relatively higher. Application for scientific research projects by humanities and social sciences postgraduates is relatively difficult, and the amount of funding for project applications is usually low. Despite the factors are complex, the concept of despising liberal arts and focusing on science objectively promotes the imbalance of the discipline awarding system.

\subsection{Single financing channel}

Owing to the constraints of many factors and conditions, some fund-raising units have a low level of fund raising and weak ability to draw social funds, resulting in a single source of funds for awards. They basically rely on government input, and the amount of grants is limited. Even if some social funds are sometimes added but it's also difficult to continue.

Educators, especially those who receive lower-level grants, and students who can't receive grants, are forced to study and carry out scientific research because of their life difficulties. Naturally, it is tough for them to succeed academically, let alone to realize the national development of high-quality and top-notch innovative personnel training requirements. 


\subsection{Limited coverage of grants}

There are deficiencies in the coverage of the recipients, where deferred students are lack of corresponding scholarship and grants. In order to encourage graduate students, especially the Doctor, to graduate on time, the training unit usually has a certain academic year limit. As a graduate student with the highest degree of academic difficulty, his research is usually more complicated and challenging. Some Doctors need to exceed the stipulated extension of the academic year to complete the research task. The training unit will no longer provide corresponding support for the learning beyond the age limit, which intangibly brings tremendous economic pressure to this group, and it is easy to induce doctoral candidates to carry out less difficult research.

\subsection{The specification loss of loans and repayments system}

The loan system is a major measure taken by the state to use financial means to improve the university's funding policy system, increasing the funding for poor college students in ordinary universities, and easing their economic difficulties. It's usually a interest-free loan, and the repayment method can be paid off in one lump sum, or it can be paid off in several installments, or deducted monthly from its salary by the unit within two to five years. However, in actual practice, they face a lot of phenomenons about losing the specification. For example, some college students maliciously delay or even fail to return loans, others are unable to repay due to graduation work problems, consequently, many conditions make the loan system face a heavy burden.

\section{Suggestions and reflections on the construction of scholarship and grants system}

Promoting a reasonable reward system is a critical guarantee for postgraduates to carry out academic research and innovation. It is a reward system that universities need to develop according to national policies and the actual construction of the school, which adapts to school's reality and promotes their continuous development. The construction of the postgraduate scholarship and grants system must comprehensively consider the following principles, including people-oriented values, the responsibility for the development of students, the suit for schools, and the promotion for the development of schools; and cultivation of talents for national reserves. Under these principles, to improve the development of this system should pay attention to the following work.

\subsection{Diversification of funding sources, steadily improving postgraduate treatment}

It's necessary to make full use of the regulatory role of the market in the allocation of educational resources. Based on the state's overall allocation, we will actively seek social support from social circles, absorb funding from companies, and encourage outstanding alumni to contribute to and support their alma mater, and steadily improve graduate students' treatment. For the family impoverished students, they can open up a "green channel" and offer them work and opportunities such as research assistants, assistant teachers, and teaching assistants to ensure their basic living and academic requests. If the conditions are ripe, a certain amount of funding can be given to postgraduate doctoral students to ensure that they can bury themselves into studies and researches, and urge them to complete the graduation requirements as soon as possible.

\subsection{Establishing a perfect incentive mechanism for graduate students}

The incentive mechanism is a crucial measure to stimulate graduates' enthusiasm for learning and research potential. Combining with the time changes, fully considering the current ideological concepts, learning attitudes, and the demand of postgraduates, it's significant to actively strengthen the relevant propaganda of the awarding system, reform assessment methods for rewards, improve the evaluation system for awards, strengthen the supervision of award assessment, and standardize the reward system management,and optimize incentives and incentives, seek balance between material rewards and spiritual incentives, results awards and process incentives, external rewards and self-motivation. 


\subsection{Balanced development between different categories and disciplines}

It should to guide the managers and researchers to change the concept of "pay attention to science but ignore humanity" dedicated to eliminate discipline biases and discrimination,and actively take measures to create regular exchange platforms between different disciplines, innovate cooperation and exchange mechanisms in different disciplines, continuously reduce the gaps between different categories and disciplines, and promote the coordinated advancement and common development of different categories and disciplines. At the same time, humanities and social sciences should minimize the application for project restrictions as far as possible and moderately increase their funding requirements.

\subsection{Strengthening postgraduates' ideological and moral education}

Graduate students as highly educated talents, if their ideological and moral qualities don't keep up, will not only fail to benefit the society, but will also cause adverse social influence. The credibility crisis in the loan system is attributed to the students' moral quality to a large extent. To strengthen students' ideological and moral education, schools should regularly carry out ideological education discussions, cultivate their moral sentiments, ethical responsibilities and awareness, and positively conduct social practice activities so that students can deepen their social practice and realize moral ideology in practice.

The postgraduate scholarship and grants work is an important part of the graduate student training mechanism reform, which plays an important role in optimizing the discipline structure, rationally disposing the disciplinary resources, strengthening the depth of academic research, and shaping high-quality talents. Many colleges and universities actively explore and practice, and have achieved certain practical effects. However, it is undeniable that the university's scholarship and grants system still has problems in different degrees. The construction of the university's scholarship and grants system must incorporate the changes in the policy situation, focus on the student development and the cultivation of high-quality personnel, continuously innovate postgraduate training models, and strengthen quality assurance.

\section{Acknowledgment}

This article is one of the phased results of education innovation program for graduate students in Shandong "Research on the causes of academic anomie and its governance" (SDYY16018), Education innovation program for graduate students of University of Jinan "research on current situation,problems and supporting system of education for graduate students"(JDYY1603).

\section{References}

[1] Cuiyu Cheng. Practice and Reflections on the Reform of Postgraduate Grants System [J]. Degree and Graduate Education, 2015, (12): 33-36.

[2] Yaoyuan Shi, Yi Lu . The Exploration and Practice of the Reform of Postgraduate Award System_-Taking Xidian University as an Example[J]. Degree and Graduate Education, 2015, (03): 54-58.

[3] Min Wang, Xilin Hou, Zhiyou Yao. Construction and Practice of Postgraduate Grant System under the New Situation [J]. Degree and Graduate Education, 2015, (03):58-62.

[4] Mingli Liu, Hu Yang, Lin Zhang, Wei Zhou. On the adjustment and control function of the award-winning work in the reform of postgraduate training mechanism—-Taking Peking University postgraduates as an example [J].Graduate Education Research.

[5] Yinghua Luo. Rational allocation of resources, and the use of postgraduates as a rewarding system for incentives: Take Fudan University as an example[J]. Graduate Education Research, 2011, (01): 16-19. 